\title{
Covid-19 and Domestic Violence: an Indirect Path to Social and Economic Crisis
}

\author{
Amalesh Sharma ${ }^{1} \cdot$ Sourav Bikash Borah ${ }^{2}$ \\ Published online: 28 July 2020 \\ (C) Springer Science+Business Media, LLC, part of Springer Nature 2020
}

\begin{abstract}
Purpose: We intend to identify the links between Covid-19 and domestic violence, expose the potential reasons behind an increase in domestic violence cases due to Covid-19, and argue that rising incidence of domestic violence may lead to economic and social crisis. Method: This is a brief note in which authors rely on various statistics and insights regarding domestic violence since the detection of Covid-19. Based on the available statistics regarding domestic violence prevalence during previous times of uncertainty, the number and nature of domestic violence incidents around the globe, and existing literature, the authors argue that clear links exist between Covid-19 and domestic violence, which also impacts on the economic and social crisis. Results: Countries across the world are battling Covid-19 by enacting measures to reduce the speed of transmission. Multiple reports, however, suggest that such measures are increasing the incidence of domestic violence and not only in number but also in severity. We find that layoffs, loss of income, extended domestic stays, and exposure to habits due to stay-at-home orders are driving up the incidence of domestic violence. Moreover, these domestic violence increases are driving economic and social crises due to the form and severity of the violence, the burden placed on government, a crisis of resources, and decreases in the productivity of workforces. Conclusion: Domestic violence increase resulting from Covid-19 is an indirect driver of economic and social crisis. This brief note proposes certain policy changes and strategies required to reduce domestic violence incidence during this turbulent time.
\end{abstract}

Keywords Economic crisis $\cdot$ Social crisis $\cdot$ Covid-19 $\cdot$ Domestic violence $\cdot$ Effective strategies

\section{Introduction}

Countries across the world are battling Covid-19 by enacting measures such as national quarantines, border closures, online work, and school closures to reduce the speed of transmission. ${ }^{1}$ As of May 7, 2020, more than one-third of the entire population of the world is under some form of restriction, with measures varying from region to region. For example, while

\footnotetext{
${ }^{1}$ https://www.businessinsider.com/countries-on-lockdown-coronavirus-italy2020-3\#germany-is-slowly-reopening-though-its-also-seen-the-infection-raterise-1
}

Amalesh Sharma

asharma@mays.tamu.edu

Sourav Bikash Borah

souravb@iima.ac.in

1 Mays Business School, Texas A\&M University, College Station, TX 77843, USA

2 Indian Institute of Management Ahmedabad, Ahmedabad, India the United States has enacted lockdowns regionally, countries such as Italy enforced citizens to stay indoors indefinitely. ${ }^{2}$ As of June 10, 2020 [at 9:12 AM CST], the total cases of Covid19 are numbered at 7,357,153, with the United States recording the most cases at 2,047,147, Brazil in second place with 742,084 cases, and Russia in third place with 493,657 cases. $^{3}$ Furthermore, looking beyond these numbers shows us that Covid-19 has affected families, relationships, and societies in unprecedented ways, leading to an economic crisis. Covid-19 is putting societies to the test to the extent that goes above and beyond political leadership, healthcare infrastructure, social care systems, and international solidarity. ${ }^{4}$ One such significant impact that is currently being felt to an alarming extent is the effects of increases in domestic violence cases during the pandemic.

\footnotetext{
$\overline{2}$ https://www.express.co.uk/news/world/1262677/Coronavirus-travel-fulllist-countries-on-lockdown

${ }^{3}$ https://www.worldometers.info/coronavirus/?utm_campaign= homeAdvegas 1 ?\% 20

${ }^{4}$ https://www.thelancet.com/journals/lanpub/article/PIIS2468-2667(20) 30097-9/fulltext\#coronavirus-linkback-header
} 
Although the lockdowns and movement restrictions imposed by countries around the world are slowing down the infection rate of Covid-19, data suggests that "domestic abuse is acting like an opportunistic infection, flourishing in the conditions created by the pandemic." ${ }^{5}$ Research suggests that social isolation is one of the most prominent tactics used by abusers to distance victims from their support networks (Coohey 2007; Menjívar and Salcido 2002). Now that physical isolation is a government-sanctioned approach; it is seen that cases of domestic violence have increased significantly (van Gelder et al. 2020). For example, in the United States, the National Domestic Violence Hotline is reporting a significant surge in calls from victims ${ }^{6}$ as are numerous other portals and government organizations.

In this study, building on the existing literature, as well as market-based facts and statistics, we expose the reasons behind increases in domestic violence rates as a result of a pandemic, together with how the increase affects economic and social changes, and what we can do to prevent the adverse effects. Moreover, we provide strategic recommendations for governments, policymakers, sociologists, and victims to tackle the negative effects of domestic violence on society, economy, and people.

\section{Related Literature}

A growing stream of literature has highlighted that there is an increase in domestic violence cases during Covid-19. In their recent research, Bradbury-Jones and Isham (2020) identify the paradoxical effects of a pandemic in this context. A recent article from The Guardian ${ }^{7}$ reports on the surge in domestic violence and emphasizes a pattern that can be observed globally. This includes a rise of $40-50 \%$ in domestic violence incidents in Brazil, a spiking in calls to helplines in Spain and Cyprus by $20-30 \%$ within the first few days of the confinement period and also within a week after the first Covid-19 patient was diagnosed, and a $25 \%$ increase in calls related to domestic violence cases in the UK within a week after strict social distancing and lockdown measures were enacted. ${ }^{8}$ Regarding the effects of Covid-19 on domestic violence in the USA, Boserup et al. (2020) show that some states have experienced a spike in cases, for example, Portland experiencing a $22 \%$ increase in arrests related to domestic violence, Jefferson County Alabama experiencing a 27\% increase in

\footnotetext{
${ }^{5}$ https://www.nytimes.com/2020/04/06/world/coronavirus-domesticviolence.html

${ }^{6}$ https://www.kalb.com/content/news/Domestic-violence-calls-increaselocally-nationwide-during-COVID-19-pandemic\%2D\%2D569689371.html

${ }^{7}$ https://www.theguardian.com/society/2020/mar/28/lockdowns-world-risedomestic-violence?CMP=Share_iOSApp_Other

${ }^{8}$ BBC. (2020). Coronavirus: Domestic Abuse Calls up 25\% Since Lockdown, Charity Says. Available at https://www.bbc.co.uk/news/uk-52157620
}

domestic violence calls during March 2020 compared to March 2019, and New York City experiencing a 10\% increase in domestic violence calls during March 2020 compared to March 20199. ${ }^{10}$

Besides, it has been noticed that multiple other studies, either published in academic outlets or in the process of development, also show that Covid-19 is having an impact on domestic violence. However, investigating the impact of a pandemic or an epidemic on domestic violence is not new. For example: Decker et al. (2013) investigated the potential HIV epidemic impact on female abuse; Mukherjee (2007) related structural violence and poverty to the AIDS pandemic; and Pellowski et al. (2013) showed how the US HIV pandemic led to social disadvantages for different racial and gender groups, resulting in violence. However, the stream of literature investigating the relationship between a pandemic and domestic violence is yet to comment on how the effects of a pandemic on economic and social crises are realized through domestic violence, which we look to expose via our study.

Moreover, similar to a pandemic, the effects of natural disasters on domestic violence have been investigated. Wilson et al. (1998) and Parkinson (2019) commented on domestic violence occurring after a disaster; Enarson (1999) reported that violence against women increases in communities hit by environmental disasters; Rahman (2013), in the context of Bangladesh, argued that the general effects of natural disaster and lack of healthcare post-disaster make women vulnerable to reproductive and sexual health issues and increase the incidents of domestic and sexual violence; and Gearhart et al. (2018) exposed the impact of natural disasters on domestic violence using an analysis of simple assault reports from Florida between 1999 and 2007.

Whether it is a pandemic or a natural disaster, domestic violence rates are affected. However, there is limited research available exposing the reasons behind such effects and, more importantly, how they come to influence the expected economic and social crisis.

\section{The Current Study}

Given the research gaps in the literature, our study is focused on answering the following questions:

1. What contributes to surges in domestic violence incidents occurring globally since the emergence of Covid-19?

2. How do increases in domestic violence incidents relate to social and economic crises?

\footnotetext{
${ }^{9}$ https://www1.nyc.gov/site/nypd/stats/reports-analysis/domestic-violence. page

${ }^{10} \mathrm{https}: / /$ jeffcosheriffal.com
} 
3. What should communities, victims, and governments do to reduce the number of incidents and mitigate the negative effects of violence on society and the economy?

To answer these questions, we rely on extant literature, market-based facts, and statistics gathered post-emergence of Covid-19. We have also attempted to collect qualitative data from the service providers responsible for responding to the domestic violence challenges in order to understand their experiences, their perspectives on the suggestions we come up with, and what they want communities to know. However, due to the ongoing effects of Covid-19, as reflected in the closures of various providers, we have not been able to gather enough information from multiple providers to include as a section. Moreover, many of the providers declined to respond to our calls due to organizational restrictions and confidentiality commitments. We were, however, successful in contacting a few providers in the United States, Bangladesh, and India through their helpline numbers. A few comments that we received from two of these providers (who agreed to comment on the status of domestic violence due to our commitment to maintaining confidentiality) are integrated with various sections of the study. As such, we provide a brief report that outlines an increase in domestic violence cases resulting from Covid-19. In the next section, we discuss the relevant analysis.

\section{Analysis}

\section{Reasons behind Increases in Domestic Violence Due to Covid-19}

Because of Covid-19 causing most countries to impose some restrictions on physical distance, domestic violence will increase, which is consistent with the understanding that "domestic violence goes up whenever families spend more time together, such as the Christmas and summer vacations.". ${ }^{11}$ As identified by sociology and gender literature, there is a direct relationship, which means that, when families spend more time together, violence may occur without any specific reason - a dynamic that can be attributed to human psychology (Booth 2017; Nofziger and Kurtz 2005). However, Covid-19 can be considered to be an indirect causer of violence.

As infection due to Covid-19 increases, countries are forced to place restrictions on certain aspects of movement - a strategy that has led to layoffs, loss of jobs, and income. Scholars have suggested that low income is related to increases in domestic violence (Peprah and Koomson

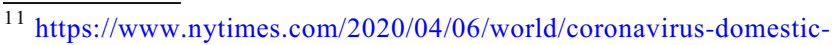
violence.html
}

2017). First, even if a family does not have a history of abuse, economic distress during a pandemic due to financial strain and a lack of social support can fuel violence. This is consistent with the literature ${ }^{12}$ that high-stress levels among couples increase the rate of violence 3.5 times more than among those with low-stress levels. Second, domestic violence may be driven by a shift in responsibilities. With changes in the responsibilities, when victims are with abusive partners, there is an opportunity for abusers to harass them. Recent research has suggested that lockdown scenarios raised by rare events like natural disasters and pandemics put families in close contact for prolonged periods; this reduces the safe time available (i.e., due to one person going to work) and increases the chances of domestic violence occurring. ${ }^{13}$ Third, domestic violence may occur as increased interactions (also due to spending more time together) expose various habits that may not be compatible with each other in a family setup.

\section{Impact of Domestic Violence on Economic and Social Environments}

While there are likely to be additional reasons for increases in violence due to Covid-19, it is clear that increases in domestic violence incidents will contribute to economic and social crises. First, in terms of social crisis, before Covid-19, victims had access to support from family and relatives, sheltered homes, and even legal remedies such as protective orders. During a lockdown, however, such options become no longer readily available. Given that victims cannot leave their home, the intensity of violence and suffering they experience is likely to increase. Second, domestic violence will affect children significantly. Due to increases in incidents, not only it can be challenging for parents to get support from family and community but losing childcare is also a considerable loss for victims as it creates more stress/responsibility for both parties (victim and children). This is coupled with the fact that areas under containment may not even be accessible to childcare services, which will increase the challenges that children face-their food and education, as well as their overall development. Plus, increased violence among parents and negative interactions due to lockdown may affect children mentally (Browne and Finkelhor 1986; Finkelhor 2010; Wood and Sommers 2011). Third, Covid-19's impact on domestic violence will also be realized via a person's social relationships with others. The relationship here refers to connections with social peers like friends, external family members, neighbors, and coworkers. Prior literature suggests that domestic violence affects maternal-child relationships, the functioning of preschool-age

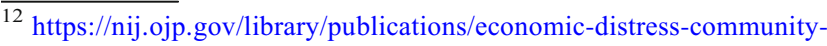
context-and-intimate-violence-application-and-0

${ }^{13} \mathrm{https}$ ://ukenreport.com/domestic-violence-cases-may-surge-in-valley/?cnreloaded $=1$
} 
children, and young people's relationships (Flood and Fergus 2008; Levendosky et al. 2003). With lockdown in place and an inability to contact social peers, victims face losing social connections. Co-workers' support is integral to supporting victims of domestic violence but Covid-19, which has enacted workfrom-home or remote working on a mass scale, is affecting people's social circles, their daily conversations and, more importantly, preventing in-person support teams from continuing their roles and helping victims to survive abuse (Goodman et al. 2016; MacGregor et al. 2016; Rogers et al. 2019). These issues are particularly challenging for socio-economically backward communities such as women of color, women from weak strata of the society and immigrants, who because of both structural and cultural reasons may not have access to support from the government and community even before the pandemic (Sokoloff and Dupont 2005; Tam et al. 2016). Post-pandemic, therefore, challenges for such communities may grow even further, and we may see a world with social imbalances accelerating across multiple streams.

Economically, increases in violence require governments to take actions - governments will need to arrange safeguarding for people affected by violence either by keeping them in isolated places or providing them some form of security - and doing so demands investment, itself another potential economic hazard (Heath 2012; Houghton 2009). Consistent with the literature suggesting that intimate partner violence rates are highest in the poorest neighborhoods (Bonomi et al. 2014; Kiss et al. 2012), Covid-19 is expected to drive domestic violence across societies due to losses in income (Purvin 2003; Williams and Mickelson 2004). As a result of domestic violence, more separations and divorces are likely, meaning that government resources will be employed, placing another strain on the economy (Moon and Joung 1997). The adverse effects of domestic violence on physical and mental health are well documented in the literature, which may range from depression, risky sexual behavior, and substance abuse to more longterm challenges like chronic diseases (Delara 2016; Friis et al. 2019; Rivara et al. 2019). More importantly, because of domestic violence, countries face losing a productive workforce that may otherwise contribute to the economy but is instead taken away by the mental and physical effects of domestic violence. This long-term effect may not be realized in a day or two, but it is inevitable nevertheless.

One of the unique things about Covid-19 and domestic violence is that economic issues are causes and consequences. For example, one may suspect that such relationships between domestic violence and economic distress are rooted in factors like mental illness ${ }^{14}$ - though establishing a causal link is technically challenging as the economic causes, violence and economic consequences move simultaneously, and many

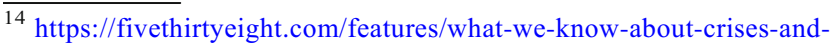
domestic-violence-and-what-that-could-mean-for-covid-19/
}

other issues may be responsible for the dynamic. Nevertheless, with the number of domestic violence cases in some of the worst-hit regions and the economic turbulence regions are facing under the current scenario, we can confirm that economic issues arising during the Covid-19 crisis are the most significant contributors to the surge in domestic violence.

Pandemics such as Covid-19, or similar rare events, increase the rate of domestic violence and the severity of abuse. For example, in 2011, New Zealand saw increases in domestic violence by a fifth after the Christchurch earthquake ${ }^{15}$ - the reason cited was the changes in alcohol consumption at home due to business closures. Whereas during Hurricane Katrina, temporary shelter enabled increases in sexual violence ${ }^{16}$ most of these assaults were caused by strangers. Indeed, sexual assaults after Hurricanes Katrina and Rita were severe, "rapes appeared to be more brutal, often involving multiple offenders" ${ }^{17}$ with the occurrences of domestic violence only dropping down to normalcy a year after the hurricane.

Given the impact of Covid-19 on domestic violence and economic and social crisis, as discussed above, we need to design policies and strategies to help us mitigate the adverse effects on the economic and social environment. In the next section, we outline a few recommendations.

\section{Strategic Recommendations}

\section{Strategies to Combat Negative Effects of Covid-19 on Domestic Violence}

While recent reports (Peterman et al. 2020) suggest some of the strategic steps that must be taken — such as bolstering violence-related first-response systems, ensuring domestic violence is integrated into healthcare response systems, expanding and reinforcing social safety nets, offering shelter, temporary housing, encouraging temporary social support networks and integrating domestic violence into the pandemic preparedness strategies - we build on the Peterman et al. (2020) recommendations, offering insights from our analysis, and extant literature to provide strategic recommendations in terms of actions to be taken by policymakers, governments, and victims that may help us to curve the ill effects of Covid19 on domestic violence intensity and severity, as well as to help to ensure economic and social stability.

\footnotetext{
${ }_{15} \mathrm{https}: / / \mathrm{www}$. nzherald.co.nz/nz/news/article.cfm?c_id=1\&objectid= 10710230

16 https://muse.jhu.edu/article/256898/pdf

${ }^{17} \mathrm{https}: / /$ muse.jhu.edu/article/256898/pdf
} 


\section{Improving Reporting of Domestic Violence}

Prior research shows that, unlike other forms of violence, domestic violence cases are more likely to be reported by victims and often after the suspect has left the crime scene (Campbell et al. 2017). This issue is particularly problematic during Covid-19 as victims may often not get a chance to report because the perpetrators remain with the victim due to lockdown restrictions. As the victims may not be able to report crimes, the roles of neighbors, community members, and other bystanders become more vital. Scholars argue that an effective way of tackling this issue is by training such groups about domestic violence (Katz and Moore 2013). Educating neighbors to sound alarms in such situations, for example, may make a significant difference in achieving higher reporting rates. This training can be conducted through government agencies or even through advertising, encouraging community members to report cases of domestic violence in their neighborhoods.

Research also shows that messaging plays a vital role in achieving higher levels of success in this context. A positive message that focuses on a solution (bystander behavior) is more effective than a negative message that focuses on the problem (domestic violence) (Katz and Moore 2013). Thus, communicating the desired bystander behavior may increase the reporting of domestic violence cases. This notion is supported by the comments of one of the respondents on our questions regarding coordination with victims, who states: "It has been a troublesome issue for coordination. Most victims need on-site supports; however, we have not been able to provide these due to closures. No mandate has been issued so far on how to handle this; we are trying to do our best to coordinate and provide assistance. Improving reporting is the task and increasing coordination is the way." To answer these issues, policymakers and governments may install rules and regulations for flexible reporting and immediate actions so that victims can come forward to seek help. Often, a victim does not come forward due to extensive paperwork and the long time required for reporting. Flexibility in providing the required information, therefore, and reducing waiting times for reporting will help to make reporting easier. If neighbors, community members, and other bystanders do their part in timely reporting, alerting law enforcement agencies, informing self-help and online support groups, etc., the severity and continuity of violent behavior can be reduced.

\section{Speed Is Most Important}

If reporting is the first $\operatorname{cog}$ in the wheel, then the speed at which law enforcement may take action against the culprit is the second. Research, however, shows that although suspect identification is more likely when the suspect and the victim are related, arrests are more likely when victims and suspects are strangers (Tasca et al. 2013). In fact, it is quite typical that the prior history of the victim (such as those involving drug abuse) may also delay arrests. This is particularly problematic during Covid-19 as a delay in arrest likely leads to the victim and the suspect sharing spaces. Due to lockdown and social distancing measures, it may be difficult to separate the two parties if legal actions are not carried out quickly.

It is also essential to communicate to the population the speed at which an arrest will occur for such a crime. This can encourage both victims and bystanders to report against domestic violence - a notion that is supported by comments from one of the respondents: "We are trying to visit them if they are not in an area with multiple cases." While another respondent commented, "We are speeding up our initiatives as this is the only way to reduce the abuse." Furthermore, another respondent informed us that "Covid-19 came without signals; we did not have preparations. Responding to incidents needs resources and, if we want to respond quickly, we need more resources. With some external funding, we have enacted a speedy responding but are yet to see its results." Given that speed of response is critical, policymakers must include responses to domestic violence with the pandemic response agenda, including providing the key resources (e.g., financial funding, human resources, and law-enforcing power related to domestic violence cases) to government organizations so that response speed can be increased. Moreover, victims should be provided a time window within which they are guaranteed to receive support. This will provide assurance to victims that, despite any resource constraints, legal support will be obtainable for them. Some victims may not want to take legal actions or have police involvement because of multiple reasons including fear of status loss and embarrassment, protection of the perpetrator from prosecution by the law, fear of retaliation, opportunity cost, victims' own criminal past, etc. (Felson et al. 2002; Rodriguez et al. 2001). In such cases, attempts to reduce the effects of violence on victims be speeded through self-help groups, friends, and online support groups.

\section{Understanding Heterogeneity}

A strategy is required to identify whether the vulnerable are also experiencing a higher proportion of violence. One such community that is particularly vulnerable is the migrant community (Choi and Byoun 2014). Because of lockdown, it may not be feasible for these communities to return to their native places. Again, as job opportunities become limited, they are more likely to face abuse and may not even report the issue. The migrant population also faces multiple forms of discrimination, including cultural discrimination, stigma, outgroup bias, etc. Furthermore, additional victim populations who are more vulnerable to Covid-19 are people with a higher risk of severe illness, immunocompromised individuals, older adults, and people with pre-conditions such as asthma, HIV, liver 
diseases, ${ }^{18}$ etc. Thus, during Covid-19, these communities require special treatment. One such solution is the antioppressive model, which educates vulnerable communities about the necessary services and resources required to live safely away from domestic violence (Dominelli and Campling 2002). Such practices reduce power imbalance and may also positively affect the likelihood of reporting. One of the respondents informed us that: "It is in the interest of victims to know who they are. If they belong to vulnerable groups, we should be careful. It is not only the effect of Covid19 but also the effect of abuse that may make their lives troublesome. Policies are required to curve out such situations." For the policymakers, it is critical to place extra attention on the vulnerable group either by creating awareness or by isolating and providing care. For victims that belong to vulnerable groups, informing their status upfront to the service providers will help them to obtain prioritized services. For the service providers, in the interest of vulnerable groups, the creation of a special response group, a special hotline number, and a special service procedure will help to curve the negative impacts.

\section{Establishing Digital Monitoring}

Most countries are utilizing the digital monitoring of their citizens during the Covid-19 crisis. Specialist apps can be used to track potential suspects as well and can be activated with an SOS system that may allow the complainants to report issues associated with domestic violence. Governments should strive to keep hotlines open 24/7. Initially, this strategy may be costly, but it has long-term social and economic benefits. The prevalence of digital monitoring is the next course of action that providers should think of, as highlighted in the comments of one of the providers we contacted: "We know that digital monitoring is the way forward. We are starting to develop a digital monitoring program and expect that it will help the victims soon. Note that calls are increasing day by day." As the world moves toward a revolution of "everything digital," establishing digital monitoring is a must. In this context, policymakers and governments should be supportive of new service modes for victims, while service providers should engage in the creation and implementation of a digital reporting system, which victims and communities should look to adapt to.

\section{Building Psychological Capital}

One of the fundamental reasons for domestic violence is a lack of economic well-being. Research of well-being suggests that creating positive psychological capital (including hope,

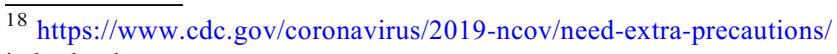
index.html
}

resilience, optimism, and self-efficacy) is vital for creating a positive future (Luthans et al. 2006). Although no research has yet focused on understanding psychological capital in cases of domestic violence, maintaining a positivity toward the future may be important when the environment is so uncertain. Rather than a reactive approach (acting after violence has occurred), a proactive approach to combat domestic violence during Covid-19 may help to reduce social and economic crisis.

\section{Conclusion}

Covid-19 is an exogenous shock that is significantly impacting the incidence of domestic violence around the world. While nobody had predicted that the world would see such an increase in the number of cases, it is time for law enforcement organizations, governments, and society, in general, to come together to design effective strategies to combat the adverse effects of Covid-19 on domestic violence. With this article, we propose a few strategies that may be effective in such a fight against domestic violence due to Covid-19 and any future rare events.

\section{References}

Bonomi, A. E., Trabert, B., Anderson, M. L., Kernic, M. A., \& Holt, V. L. (2014). Intimate partner violence and neighborhood income: A longitudinal analysis. Violence Against Women, 20(1), 42-58.

Booth, C. (2017). Keeping families together: The Homebuilders model: Routledge.

Boserup, B., McKenney, M., \& Elkbuli, A. (2020). Alarming trends in US domestic violence during the COVID-19 pandemic. American Journal of Emergency Medicine.

Bradbury-Jones, C., \& Isham, L. (2020). The pandemic paradox: The consequences of COVID-19 on domestic violence. Journal of clinical nursing., 29, 2047-2049.

Browne, A., \& Finkelhor, D. (1986). Impact of child sexual abuse: A review of the research. Psychological Bulletin, 99(1), 66-77.

Campbell, A. M., Hicks, R. A., Thompson, S. L., \& Wiehe, S. E. (2017). Characteristics of intimate partner violence incidents and the environments in which they occur: Victim reports to responding law enforcement officers. Journal of Interpersonal Violence, 0886260517704230.

Choi, G.-Y., \& Byoun, S.-J. (2014). Domestic violence against migrant women in South Korea: Addressing the needs of a uniquely situated victim population in domestic violence policy. International Social Work, 57(6), 645-660.

Coohey, C. (2007). The relationship between mothers' social networks and severe domestic violence: A test of the social isolation hypothesis. Violence and Victims, 22(4), 503-512.

Decker, M. R., Wirtz, A. L., Pretorius, C., Sherman, S. G., Sweat, M. D., Baral, S. D., Beyrer, C., \& Kerrigan, D. L. (2013). Estimating the impact of reducing violence against female sex workers on HIV epidemics in Kenya and Ukraine: A policy modeling exercise. American Journal of Reproductive Immunology, 69, 122-132. 
Delara, M. (2016). Mental health consequences and risk factors of physical intimate partner violence. Mental Health in Family Medicine, 12(1), 119-125.

Dominelli, L., \& Campling, J. (2002). Anti oppressive social work theory and practice: Macmillan international higher education.

Enarson, E. (1999). Violence against women in disasters: A study of domestic violence programs in the United States and Canada. Violence Against Women, 5(7), 742-768.

Felson, R. B., Messner, S. F., Hoskin, A. W., \& Deane, G. (2002). Reasons for reporting and not reporting domestic violence to the police. Criminology, 40(3), 617-648.

Finkelhor, D. (2010). Sexually victimized children: Simon and Schuster.

Flood, M., \& Fergus, L. (2008). An assault on our future: The impact of violence on young people and their relationships.

Friis, K., Pihl-Thingvad, J., Larsen, F. B., Christiansen, J., \& Lasgaard, M. (2019). Long-term adverse health outcomes of physical workplace violence: A 7-year population-based follow-up study. European Journal of Work and Organizational Psychology, 28(1), 101-109.

Gearhart, S., Perez-Patron, M., Hammond, T. A., Goldberg, D. W., Klein, A., \& Horney, J. A. (2018). The impact of natural disasters on domestic violence: An analysis of reports of simple assault in Florida (1999-2007). Violence and Gender, 5(2), 87-92.

Goodman, L. A., Banyard, V., Woulfe, J., Ash, S., \& Mattern, G. (2016). Bringing a network-oriented approach to domestic violence services: A focus group exploration of promising practices. Violence Against Women, 22(1), 64-89.

Heath, R. (2012). Women's access to labor market opportunities, control of household resources, and domestic violence: The World Bank.

Houghton, R. (2009). Everything became a struggle, absolute struggle': Post-flood increases in domestic violence in New Zealand. Women, gender and disaster: Global issues and initiatives, 99-111.

Katz, J., \& Moore, J. (2013). Bystander education training for campus sexual assault prevention: An initial meta-analysis. Violence and Victims, 28(6), 1054-1067.

Kiss, L., Schraiber, L. B., Heise, L., Zimmerman, C., Gouveia, N., \& Watts, C. (2012). Gender-based violence and socioeconomic inequalities: Does living in more deprived neighbourhoods increase women's risk of intimate partner violence? Social Science \& Medicine, 74(8), 1172-1179.

Levendosky, A. A., Huth-Bocks, A. C., Shapiro, D. L., \& Semel, M. A. (2003). The impact of domestic violence on the maternal-child relationship and preschool-age children's functioning. Journal of Family Psychology, 17(3), 275-287.

Luthans, F., Avey, J. B., Avolio, B. J., Norman, S. M., \& Combs, G. M. (2006). Psychological capital development: Toward a micro-intervention. Journal of Organizational Behavior, 27(3), 387-393.

MacGregor, J. C., Wathen, C. N., Olszowy, L. P., Saxton, M. D., \& MacQuarrie, B. J. (2016). Gender differences in workplace disclosure and supports for domestic violence: Results of a pan-Canadian survey. Violence and Victims, 31(6), 1135-1154.

Menjívar, C., \& Salcido, O. (2002). Immigrant women and domestic violence: Common experiences in different countries. Gender \& Society, 16(6), 898-920.

Moon, S.-J., \& Joung, S.-H. (1997). Expenditure patterns of divorced single-mother families and two-parent families in South Korea. Journal of Family and Economic Issues, 18(2), 147-162.

Mukherjee, J. S. (2007). Structural violence, poverty and the AIDS pandemic. Development, 50(2), 115-121.

Nofziger, S., \& Kurtz, D. (2005). Violent lives: A lifestyle model linking exposure to violence to juvenile violent offending. Journal of Research in Crime and Delinquency, 42(1), 3-26.
Parkinson, D. (2019). Investigating the increase in domestic violence post disaster: An Australian case study. Journal of Interpersonal Violence, 34(11), 2333-2362.

Pellowski, J. A., Kalichman, S. C., Matthews, K. A., \& Adler, N. (2013). A pandemic of the poor: Social disadvantage and the US HIV epidemic. American Psychologist, 68(4), 197-209.

Peprah, J. A., \& Koomson, I. (2017). Economic drivers of domestic violence among women: A case study of Ghana Violence and Society: Breakthroughs in Research and Practice (pp. 222-240): IGI global.

Peterman, A., Potts, A., O’Donnell, M., Thompson, K., Shah, N., OerteltPrigione, S., \& van Gelder, N. (2020). Pandemics and violence against women and children. Center for Global Development working paper, 528.

Purvin, D. M. (2003). Weaving a tangled safety net: The intergenerational legacy of domestic violence and poverty. Violence Against Women, 9(10), 1263-1277.

Rahman, M. S. (2013). Climate change, disaster and gender vulnerability: A study on two divisions of Bangladesh. American Journal of Human Ecology, 2(2), 72-82.

Rivara, F., Adhia, A., Lyons, V., Massey, A., Mills, B., Morgan, E., Simckes, M., \& Rowhani-Rahbar, A. (2019). The effects of violence on health. Health Affairs, 38(10), 1622-1629.

Rodriguez, M. A., McLoughlin, E., Nah, G., \& Campbell, J. C. (2001). Mandatory reporting of domestic violence injuries to the police: What do emergency department patients think? Jama, 286(5), $580-583$.

Rogers, M., Rumley, T., \& Lovatt, G. (2019). The change up project: Using social norming theory with young people to address domestic abuse and promote healthy relationships. Journal of Family Violence, 34(6), 507-519.

Sokoloff, N. J., \& Dupont, I. (2005). Domestic violence at the intersections of race, class, and gender: Challenges and contributions to understanding violence against marginalized women in diverse communities. Violence Against Women, 11(1), 38-64.

Tam, D. M., Tutty, L. M., Zhuang, Z. H., \& Paz, E. (2016). Racial minority women and criminal justice responses to domestic violence. Journal of Family Violence, 31(4), 527-538.

Tasca, M., Rodriguez, N., Spohn, C., \& Koss, M. P. (2013). Police decision making in sexual assault cases: Predictors of suspect identification and arrest. Journal of Interpersonal Violence, 28(6), 11571177.

van Gelder, N., Peterman, A., Potts, A., O'Donnell, M., Thompson, K., Shah, N., \& Oertelt-Prigione, S. (2020). COVID-19: Reducing the risk of infection might increase the risk of intimate partner violence. EClinicalMedicine.

Williams, S. L., \& Mickelson, K. D. (2004). The nexus of domestic violence and poverty: Resilience in women's anxiety. Violence Against Women, 10(3), 283-293.

Wilson, J., Phillips, B., \& Neal, D. M. (1998). Domestic violence after disaster. The gendered terrain of disaster, 115-123.

Wood, S. L., \& Sommers, M. S. (2011). Consequences of intimate partner violence on child witnesses: A systematic review of the literature. Journal of Child and Adolescent Psychiatric Nursing, 24(4), 223-236.

Publisher's Note Springer Nature remains neutral with regard to jurisdictional claims in published maps and institutional affiliations. 